\title{
Effects of Radio waves on Haematological Parameters of Albino Mice
}

\author{
D.O. Kehinde ${ }^{1}$, O.E. Ehinlafa ${ }^{2}$, K. O. Ogunwenmo ${ }^{3}$, I.C. Ahube $^{3}$ \\ ${ }^{1}$ Basic Sciences Department, Babcock University, Ilisan-Remo, Nigeria \\ ${ }^{2}$ Physics Department, University of Ilorin, Ilorin, Nigeria \\ ${ }^{3}$ Department of Microbiology, Babcock University, Ilisan-Remo, Nigeria
}

\begin{abstract}
Electromagnetic waves consist of electric and magnetic fields, which travel / propagate through vacuum. Radio waves are a type of electromagnetic radiation that travel at the speed of light. They carry signals for television and cellular phones. Albino mice were exposed to short wave radiofrequencies around a global satellite mobile (GSM) communication system base station at 0,25 and $50 \mathrm{~m}$ in residential quarters in IlishanRemo for five weeks. This is with the objective of determining the effects of radiofrequencies on the haematological parameters of the mice. The results of the weight change experiment showed a non significant weight gain $(P<0.05)$ in the exposed and control mice groups. The haematological studies revealed that there was decrease in white blood cell (WBC) counts and slight elevation of white blood cells (WBC) counts in exposed and control mice respectively. There was however no significant $(P>0.05)$ difference between the red blood cells (RBC) counts. Thus, exposed mice might suffer reduced immunity and protection against diseases and infections.
\end{abstract}

Keywords: Electromagnetic, Radiation, Radiofrequencies, Haematological parameters, Blood cells (WRC \& $R B C)$

\section{Introduction}

Electromagnetic waves consist of electric and magnetic fields, which travel / propagate through vacuum (unlike mechanical waves which require a medium to propagate) and do not require moving charges or currents (Wolfgang and Gary, 2011).

Although we are not always aware of their presence, electromagnetic waves permeate our environment in the form of visible light which enable us to view the world around us with our eyes; infrared wave from the surface of the earth warm our environment; radar frequency wave carry our favorite radio entertainment; microwaves cook our food and are used in radar communication systems (Serway and Jewett, 2002).

Electromagnetic waves carry energy, and as they propagate through space they transfer energy to objects placed in their path. Hence it follows that pressure is exerted on a surface when an electromagnetic waves impinges on it (Serway and Jewett, 2002).

Electromagnetic spectrum includes electromagnetic waves with wavelength ranging from $1000 \mathrm{~m}$ and longer to less than $10^{-12} \mathrm{~m}$, with corresponding frequencies ranging from $10^{5}$ to $10^{20} \mathrm{~Hz}$ (Wolfgang and Gary, 2011).

Radio waves are a type of electromagnetic radiation with wavelengths in the electromagnetic spectrum longer than infrared light. Like all other electromagnetic waves, they travel at the speed of light. Naturallyoccurring radio waves are made by lightning, or by astronomical objects. Artificially-generated radio waves are used for fixed and mobile radio communication, broadcasting, radar and other navigation systems, satellite communication, computer networks and innumerable other applications (Douglas, 2015). Radio waves have the longest wavelengths in the electromagnetic spectrum. These waves can be longer than a football field or as short as a football. Radio waves do more than just bring music to your radio. They also carry signals for your television and cellular phones (Cole, 2010; Thide, 2004). Cell phone works by sending and receiving radio waves. They are the result of charges accelerating, for example, through conducting wires in a radio antenna. They are generated by such electronic devices as LC oscillators and are used in radio and television communication systems (Serway and Jewett, 2002). They have frequencies ranging from $100 \mathrm{KHz}$ (AM radio) to $100 \mathrm{MHz}$ (FM radio). They are also widely used in astronomy because they can pass through clouds of dust and gas that block visible light (Wolfgang and Gary, 2011). Mobile phone radiation has some biological effect. Even if the changes are small, they still exist. Mobile telephony uses radio waves to carry information, like voice, texts and images, through the air. The number of oscillation pre second is called the frequency (Cole, 2010; Thide, 2004).

This is the behavior of radio waves when they are transmitted from one point on the earth to another, or into various part of the atmosphere. Like light waves, radio waves are affected by the phenomena of reflection, 
refraction, diffraction, absorption, polarization and scattering. Radio waves at different frequency propagate in different ways (Cole, 2010; Lucien, 1987).

When a person is exposed to the radio waves from mobile phones or base stations, most of the energy will be reflected by the body or travel around it (called diffraction). Some of the energy will be absorbed in the tissues at the surface of the body (Cole, 2010; Thide, 2004). Water molecules in the body will start to rotate due to the presence of electromagnetic field. By friction the energy is converted to heat. If the radio wave intensity is very high, the heating may be significant potentially detrimental. The specific absorption rate, SAR, is used to specify the amount of the radio frequency absorbed in the body. SAR is expressed in the unit watt per kilogram $(\mathrm{W} / \mathrm{kg})$.Mobile phone radiation has some biological effect. Even if the changes are small, they still exist (Jihan, 2010).

A study has shown that radiation from mobile phones may cause a substantial increase in the forces that living cells exert on each other. This could provide clues on whether radiation from mobile phones is linked to cancer and other health problems (Jihan, 2010).

\section{Electromagnetic Radiation And Its Types}

Radiation is a beam or field of intense energy focused on a certain area of the body. It refers to highenergy electromagnetic waves, or particles. Radiation is generated by a radioactive substance (radioisotopes), such as cobalt, uranium, radon, and plutonium or with an atomic particle (linear) accelerator. We are constantly exposed to low- level radiation from natural sources: cosmic ray, natural radioactivity in rocks and soil, and naturally occurring radioisotopes that occur in our food (Douglas, 2015).

\subsection{Ionizing Radiation and its Effects}

This type of radiation contains enough electromagnetic energy to strip atoms and molecules from the tissue and alter chemical reactions in the body. Gamma rays and X-rays are two forms of ionizing radiation. Due to the fact that they cause damage, lead vest are worn when X-rays are taken of our bodies.

The extent of damage due to radiation exposure depends on the quantity of radiation delivered to the body, the dose rate, the organ exposed, the type of radiation, the duration of exposure, and the energy transferred from the radioactive wave or particle to the exposed tissue (Lawrence et al., 2003).

Radiation exposure produces two kinds of injury: acute (immediate) and chronic (delayed).

\subsubsection{Acute (Immediate) Ionizing Radiation Effects on Normal Tissues}

Acute radiation illness generally occurs in people whose entire body has been exposed to radiation. Acute radiation illness progresses through several stages, beginning with early symptoms (prodrome) and followed by a symptom-free period (latent stage). Various syndromes follow, depending on the amount of radiation the person received. The greater the amount of radiation, the more severe the symptoms and the quicker the progression from the early symptoms to the actual syndrome (Lawrence et al., 2003).

Injury to Skin and Mucous Membranes: Irradiation may cause erythema, epilation, destruction of fingernails, or epidermolysis (Lawrence et al., 2003; Eugene et al., 2015).

Injury to Deep Structure (Hematopoietic tissues): Hematopoietic syndrome is caused by the effects of radiation on the bone marrow, spleen, and lymph nodes - the primary site of blood cell production (hematopoiesis). Loss of appetite, lethargy, nausea, and vomiting begin 2 to 12 hours after exposure to 2 Gy or more of radiation. The symptoms resolve within 24 to 36 hours after exposure, and the person feels well for a week or more. During the symptom-free period, the blood-producing cells in the bone marrow, spleen, and lymph nodes begin to waste away and are not replaced, leading to a severe shortage of red blood cells, platelet, and red blood cells. The shortage of white blood cells can lead to severe infections. The shortage of platelets may cause uncontrolled bleeding. The shortage of red blood cells (anemia) causes fatigue, weakness, paleness, and difficulty breathing with physical exertion (Mark et al., 2003; Theml, et al, 2004).

\subsubsection{Chronic (Delayed) Ionizing Radiation Effects on Normal Tissues}

Chronic effects of radiation result from damage to the genetic material in dividing cells. These alterations may cause abnormalities of cell growth, such as cancer. In severely irradiated animals, damage to reproductive cells has been shown to lead to defective offspring (birth defects) (Mark et al., 2003; Theml, et al, 2004).

\subsection{Non-Ionizing Radiation}

Non-ionizing radiation is typically safe. It causes some heating effect, but usually not enough to cause any type of long-term damage to tissue. Radio-frequency energy, visible light and microwave radiation are considered non-ionizing (Douglas, 2015). 


\subsection{Measurement of Radiation - Dosimetry}

Radiation dose is measured in several different units, but all relates to the amount of energy deposited. The units include the roentgen (R), the gray $(\mathrm{Gy})$, and the Sievert $(\mathrm{Sv})$. The earliest unit of dosage was the roentgen $(\mathrm{R})$, which was defined in terms of the amount of ionization produced by the radiation $\left(1.6 \times 10^{12}\right.$ ion pairs per gram of dry air at standard conditions). Today, $1 \mathbf{R}$ is defined as the amount of $\mathrm{X}$ or $\gamma$ radiation that deposits $0.878 \times 10^{-2} \mathrm{~J}$ of energy per kilogram of air. The roentgen was largely superseded by rad: $1 \mathrm{rad}$ is that amount of radiation which deposits energy at a rate of $1.00 \times 10^{-2} \mathrm{~J} / \mathrm{kg}$ in any absorbed material. The proper SI unit for absorbed dose is the gray:

$$
1 \mathrm{~Gy}=1 \mathrm{~J} / \mathrm{kg}=100 \mathrm{rad},
$$

and is slowly coming into use. The Sievert and gray are similar, except the Sievert takes into account the biologic effects of different types of radiation. The absorbed dose depends not only on the strength of a giving beam (number of particles per second) and the energy per particle, but also on the type of material that is absorbing the radiation.

Bone is denser than flesh and absorbs more of the radiation normally used, the same beam passing through a human body deposits a greater dose (in rads or grays) in bone than in flesh. The gray and the rad are physical units of dose - the energy deposited per unit mass of material. The relative biological effectiveness (RBE) or quality factor (QF) of a given type of radiation is defined as the number of rads of X or $\gamma$ radiation that produces the same biological damage as $1 \mathrm{rad}$ of the given radiation. The product of the dose in rads and the QF gives a unit known as the rem (which stands for rad equivalent for man):

Effective dose (in rem) $=$ dose (in rad) $x \mathrm{QF}$.

This unit is being replaced by the SI unit for "effective dose," the Sievert (Sv). (pls, check not ":" but ".")

$$
\text { Effective dose (Sv) }=\operatorname{dose}(\mathrm{Gy}) \text { x QF (Douglas, 2015) }
$$

Because charged particles can ionize the atoms or molecules of any material they pass through, they are referred to as ionizing radiation. And because radiation produces ionization, it can cause considerable damage to materials, particularly to biological tissue (Mark et al., 2003; Theml, et al, 2004).

\subsection{Biologic Effects of Radiation}

Charged particles (such as $\alpha, \beta$ rays and protons) cause ionization because of the electric force. That is, when they pass through a material, they can attract or repel electrons strongly enough to remove them from the atoms of the material. Neutral particles also give rise to ionization when they pass through materials. The radiation damage produced in biological organisms is due primarily to ionization produced in cells. Ions or radicals are produced that are highly reactive and take part in chemical reactions that interfere with the normal operation of the cell (Douglas, 2015). All forms of radiation can ionize atoms by knocking out electrons. If these are bonding electrons, the molecule may break apart, or it may be altered so that it does not perform its normal function or performs a harmful function. In the case of proteins, the loss of one molecule is not serious if there are other copies of that particular one in the cell an additional one can be made from its gene (Douglas, 2015). However, larger dose of radiation may damage so many molecules that new copies cannot be made quickly enough, and the cell dies. Damage to DNA is more serious, since a cell may have only one copy. Each alteration in the DNA affects a gene and can alter the molecule it codes for, so that needed proteins for other material cannot be made at all(Bain, et al, 2011; Theml, et al, 2004). Again the cell may die. The death of a single cell is not normally a problem, since the body can replace it with a new one. (There are exceptions, such as neurons, which are not replaceable, so their loss is serious). But if many cells die, the organism may not be able to recover. On the other hand, a cell may survive but be defective. It may go on dividing and produce many more defective cells to the detriment of the whole organism(spacing)(Bain, et al, 2011; Theml, et al, 2004). Radiation damage to biological organisms is often separated into two categories according to its location in the body: somatic and genetic.

- Somatic damage refers to any part of the body except the reproductive organs. Somatic damage affects that particular organism, causing cancer and, at high doses, radiation sickness or even death.

- Genetic damage refers to damage to reproductive cells and so affects an individual's offspring. Damage to the genes result in mutations, of which they are transmitted to future generations (Douglas, 2015).

Radiation must produce double-strand break in DNA to kill a cell, owing partly to the high capacity of mammalian cells for repairing single-strand break damage. Radiation can also produce effects indirectly by interacting with water (which makes up approximately $80 \%$ of a cell's volume) to generate free radicals, which can damage the cell. Free radicals are highly reactive chemical entities that lack a stable number of outer-shell electrons. A free radical is not stable and has a life span of a fraction of second. It is estimated that most radiation-induced cell damage is due to the formation of hydroxyl radical, as follows:

$$
\begin{gathered}
\text { Ionizing radiation }+\mathrm{H}_{2} \mathrm{O} \rightarrow \mathrm{H}_{2} \mathrm{O}^{+}+\mathrm{e}^{-} \\
\mathrm{H}_{2} \mathrm{O}^{+}+\mathrm{H}_{2} \mathrm{O} \rightarrow \mathrm{H}_{3} \mathrm{O}^{+}+\mathrm{OH} \\
\mathrm{OH} \cdot
\end{gathered}
$$


The result of radiation damage is cell death. The biologic effects on epithelial cell reproduction are expressed only when the damaged cells attempt to divide (Eugene et al., 2015).

Chromosome breaks occur when cells are irradiated. The broken ends combine with broken ends of different chromosomes. These abnormal combinations are most readily seen during mitosis. Chromosome abnormalities typically occur in cells irradiated in the G1 phase of the cell cycle, before the doubling of genetic material. If cells are irradiated in the G2 phase, chromatid aberration may result(spacing)(Bain, et al, 2011; Theml, et al, 2004). The frequency of chromosomal aberrations in peripheral circulating lymphocytes correlates with the dose received. The dose can be estimated by comparing the chromosomal changes to in vitro cultures exposed to controlled dose of radiation. The minimum dose can be detected by peripheral lymphocyte analysis is about 0.1 to $0.2 \mathrm{~Sv}$ (10 t0 $20 \mathrm{rem}$ ).Lymphocyte analysis may provide evidence of recent total-body exposure (Eugene et al., 2015; Theml, et al, 2004).

\section{Materials And Methods}

The materials used for this study are enlisted below:

- 20 male albino mice

- Wooden cages

- Surgical gloves

- Radiofrequency meter

- Slides

- Microscope

- GLO - GSM Base station

- EDTA bottles

- Lithium heparin bottles

- $2 \& 5 \mathrm{ml}$ syringes

- Cotton wool

- Methylated spirit

- Dissecting set

- Plastascine

Food Consumption Materials:

- Crude protein 16.00

- Fats/oil 5.00

- Crude fiber $\quad 7.0$

- Calcium 1.50

- Available phosphorus 0.45

- Lysine 0.15

- Methionine 0.36

- Salt (min) 0.30

- Kcal/kg Metabolizable energy (min) 2450

- Net wt/kg 25

The method employed in administering the above materials is as follows:

Two locations were used for the study, station 1 was a GLO - GSM base station located around a residential quarter in Ilishan town and the second site (control station) was located away from any GSM base station at the farm house, Babcock University.

\subsection{Animal Breeding, Maintenance and Blood Parameters Measurement}

Albino mice, Musmusculus, which served as the bioassay organisms, were purchased from OSUTH at Sagamu and were fed morning and evening with grower mash and water from Topfeeds made from corn and sorghum. They were kept in wooden cages (height 10 inches, length 2 feet \& breadth 14.5 inches) for two weeks to acclimatize to laboratory conditions before commencement of bioassay. Body weight of the mice was recorded.

Weight of each mouse was taken before and after three weeks of exposure with the aid of electronic beam balance. The average weight gain or loss for each test animal per group was determined.

Two per group were harvested after three weeks of exposure from the base station and control and the last three per group after four weeks of exposure for analysis, the mice were killed through cervical dislocation.

Blood was collected from the heart of the test and control animals using syringes of 5ml into EDTA anticoagulant bottle. The blood was diluted in $10 \mu \mathrm{l}$ of blood sample to $190 \mu \mathrm{l}$ of turk's solution using 
micropipette to aspirate blood from the test tube in order to haemolyse the red blood cell therefore ensuring that only the white blood cells are being enumerated. White blood cells were counted microscopically using an improved Neubauer ruled counting chamber (haemocytometer). Micropipette was used to drop blood solution on the haemocytometer and was charged with water and cotton wool in a petri-dish. A compound microscope was used to count and the number of white blood cells per litre of blood was calculated.

Blood was collected from the heart of the test and control animals using syringes of $5 \mathrm{ml}$ into EDTA anticoagulant bottle. The capillary tubes were three-quarters filled with well mixed blood from the EDTA bottle. One end of the tubes was sealed with plastascene and was placed in the hematocrit centrifuge and was centrifuged at 15,000 rpm for five minutes. The tubes were then placed in the hematocrit reader and were red. The reading was expressed as a percentage of packed red cells in the total volume of whole blood (Bain, et al, 2016; Eugene et al., 2015).

\subsection{Measurement of Radiofrequency Radiation from GSM Base Station}

Mice were divided into four groups containing 5 mice each (all males). Each group was placed in the wooden cage and placed at the designated location. Total exposures due to radiofrequency field strength from the mobile phone base station and the control station, were measured with the aid of a wide spectrum Aerialia Radiofrequency Field Strength measuring meter at distances of 0 meter, 25 meters, 50 meters and control site (about 500 meters away).

\section{Results And Discussion}

The results of the RF measurements are presented in Table 4.1. The highest level of RF radiation based on electric field strength was detected at the 25 meters location within the residential quarter. The RF of 0 meter location was found to be closer to the 25 meters while that of 50 meters was not far from that of the control site.

There was no reduction in their food and water intake, they ate normally.(spacing)All the mice survived and there was no injury during and after the exposure.

The result of the weight changes experiments presented in Table 4.2 showed that over the three and four weeks of observation, there was weight gain in the mice exposed to radiation from GSM base station and those in the control site. Statistical(spacing)comparison of mean weight changes between exposed mice and control mice showed that there were no significant differences $\mathrm{P}>0.05$ between the weights of the test animals. Increase in weight is as a result of water and feed consumption and not exposure to radio waves.

Table 4.1: Radio Frequency measurement $(\mathrm{mV} / \mathrm{m})$ at the four locations

\begin{tabular}{|l|l|l|l|l|}
\hline RF Measurement/Max & $\begin{array}{l}\text { Control } \\
(\mathrm{mV} / \mathrm{m})\end{array}$ & $\begin{array}{l}0 \text { meter } \\
(\mathrm{mV} / \mathrm{m})\end{array}$ & $\begin{array}{l}25 \text { meters } \\
(\mathrm{mV} / \mathrm{m})\end{array}$ & $\begin{array}{l}50 \text { meters } \\
(\mathrm{mV} / \mathrm{m})\end{array}$ \\
\hline $1^{\text {st }}$ Measurement & 15.7 & 21.7 & 49.2 & 15.7 \\
\hline $2^{\text {nd }}$ Measurement & 12.3 & 19.6 & 52.5 & 17.3 \\
\hline $3^{\text {rd }}$ Measurement & 13.3 & 13.3 & 29.8 & 18.5 \\
\hline
\end{tabular}

Table 4.2: Mean weight change in mice exposed to RF radiations and control over the four weeks period of observation.

\begin{tabular}{|l|l|l|l|}
\hline Distance & Week one & Week three & Week four \\
\hline Control & $241.80 \mathrm{~g}$ & $308.65 \mathrm{~g}$ & $222.78 \mathrm{~g}$ \\
\hline $0 \mathrm{~m}$ & $42.40 \mathrm{~g}$ & $122.95 \mathrm{~g}$ & $119.73 \mathrm{~g}$ \\
\hline $25 \mathrm{~m}$ & 155.80 & $265.90 \mathrm{~g}$ & $205.55 \mathrm{~g}$ \\
\hline $50 \mathrm{~m}$ & $243.70 \mathrm{~g}$ & $307.88 \mathrm{~g}$ & $284.90 \mathrm{~g}$ \\
\hline
\end{tabular}

Table 4.3 shows the values of the mean white blood cell (WBC) count of mice after three and four weeks of exposure to radio waves. There was significant difference in white blood cell count between the test animals and the control animals. The mean white blood cell count of the control animals is significantly higher than the test animals.

Table 4.4 shows the mean red blood cell (RBC) counts of mice after three and four weeks of exposure to radio waves. There was significant difference in mice located at 0 meter to the base station. There was no much difference to mice located at 25 and 50 meters away from the base station when compared with the control.

Table 4.3: White blood cell counts in mice after three and four weeks of exposure to radiation.

\begin{tabular}{|l|l|l|}
\hline & Three weeks & Four weeks \\
\hline Locations & $\mathrm{mm}^{3}$ & $\mathrm{~mm}^{3}$ \\
\hline Control & 96,500 & 4,233 \\
\hline O meter & 27,500 & 2,133 \\
\hline 25 meters & 4,800 & 5,366 \\
\hline 50 meters & 4,000 & 7,050 \\
\hline
\end{tabular}


Table 4.4: Red blood cell counts in mice after three and weeks of exposure to radiation.

\begin{tabular}{|l|l|l|}
\hline & Three weeks & Four weeks \\
\hline Locations & $\%$ & $\%$ \\
\hline Control & 37 & 46.33 \\
\hline 0 meter & 25.5 & 34.67 \\
\hline 25 meters & 38 & 44.67 \\
\hline 50 meters & 43 & 44 \\
\hline
\end{tabular}

The results of the hematological studies showed that the white blood cells counts were found to be significantly lower and some higher in mice exposed to radiofrequency radiations from GSM base station than in control mice. The decrease in white blood cell (WBC) counts of test animals may be attributed to a combination of normal environmental changes and the radiation from the base station. Since white blood cells play important role in the body's defense mechanisms against diseases (Bain, et al, 2011; Taylor et al., 1997; Polat, et al., 2003), individuals or organisms easily become susceptible to disease and infection due to decreased levels of white blood cell. The exposure of the test animals to radiation from the GSM base station had a little effect on the red blood cell value of test animal at 25 meters distance. Exposure to radiofrequency radiations could also induce stress in exposed animals which led to the synthesis of abnormally high levels of white blood cells (Douglas, 2015; Theml, et al., 2004; Quintavalla, et al., 2001). Several studies have identified the white blood cell count as an integrated indication of inflammatory stimuli on both acute and chronic time frames. It is elevated acutely by infection and other toxic exposures. Elevation of white blood cell count is said to indicate infection, inflammation, trauma, stress, and tissue destruction, disease of bone marrow or bone marrow failure (spacing)(Pococket al., 1989; Hoffman et al., 2004; Jeeet al., 2005). The red blood cells functions by transporting oxygen to the lungs and carbon dioxide away from the lungs (Taylor et al., 1997; Sami, 2014; Bain, et al, 2016), a significant decrease in red blood cell count indicate an anemic condition, fatigue, weakness, paleness, and difficulty breathing with physical exertion (Sami, 2014; Polat, et al., 2003; Mark et al., 2003).

\section{Conclusion}

This study showed that there are differences in hematological parameters observed between exposed and control mice. These observed differences were found to be linked to the strength of the electromagnetic fields and total duration of exposure. The reduction of white blood cells is an indication of interference of radiofrequency with the immune systems of exposed mice. This might have an implication for the human population around the base station.

\section{Acknowledgement}

Our profound gratitude goes to Mr. Haruna and Mr. Akinleye(spacing)of Department of Medical Laboratory Science for their immense contribution in the analysis of the blood samples of the Albino Mice in the Laboratories of the Haematology and Chemical Pathology of the Babcock University Teaching Hospital, Ilisan-Remo, Nigeria.

\section{References(spacing)}

[1]. Bain, B. J., Bates, I., Laffan, M. A. \& Lewis, M. S. (2011),Dacie\& Lewis Practical Hematology, $11^{\text {th }}$ ed, Churchill Livingstone, Elsevier Limited, Edinburg, pp. 326-328. ISBN-13: 9780702034084

[2]. Bain, B. J., Bates, I., \& Laffan, M. A.(2016), Dacie \& Lewis Practical Hematology, $12^{\text {th }}$ ed, Churchill Livingstone, Elsevier Limited, Edinburg, pp. 438-440.

[3]. Cole, P. H. (2010),Electromagnetic Theory - A simple introduction, McGraw - Hill companies, Inc. U. S. A., pp. 55 - 65

[4]. Douglas C. Giancoli (2015),Physics: Principles with Application, $6^{\text {th }}$ ed. Pearson Publishers, 839 - 843, ISBN-13: 9781292057125

[5]. Eugene, B., Stephen, L., Anthony, S., Dan, L., Dennis, K. Lorry, J. (2015), Harrison's Principles of Internal Medicine. $19^{\text {th }}$ edition McGraw - Hill companies, Inc. U. S. A. Vol. 2. P. 2585 - 2589.

[6]. Hoffman, M., Blum, A., \& Baruch, R. (2004),Leukocytes and Coronary Heart disease, Atherosclerosis 172: 1 - 6.

[7]. Jee, S., Park, Y., Kim, H., Lee, T., \&Sannet, J. (2005),White blood cell count and risk for all-cause, cardiovascular, and cancer mortality in a cohort of Koreans. American Journal of Epidemiology 162(11): 1062-1069.

[8]. Jihan. (2010),Using cell phones can be hazardous as smoking. BIOMEDME.COM

[9]. Lawrence, M., Stephen, J., Maxine, A. (2003),Current Medical Diagnosis and Treatment. $42^{\text {nd }}$ edition, McGraw - Hill Companies Inc. U.S.A. pp. 298 - 299.

[10]. Lucien, B. (1987),Radio waves Propagation. McGraw-Hill Book Company, New York, ISBN 0-07-006433-4.

[11]. Mark, B., Thomas, J., Robert, P., Michael, B., Andrews, F., Justin, L. (2003),The Merck Manual of Medical Information. $2^{\text {nd }}$ Home edition. P. 1231, pp. 1657 - 1660

[12]. Pocock, S J; Ashby, D; Shaper, A G; Walker, M; \& Broughton, P M (1989), Diurnal variations in serum biochemical and haematological measurements. Journal of Clinical Pathology 42(2): 172-179.

[13]. Polat, U., Cetin, M.,Turkyilmaz, O., \&Ak, I. (2003), Effects of dietary protein levels on the biochemical and production parameters of Ostriches (StruthioCamelus), Vet. Arhiv., 73, pp. $73-81$. 
[14]. Quintavalla, F., Bigliardi, E., \&Bertoni, P.(2001),Blood biochemical baseline values in the Ostriches (StruthioCamelus),Ann. Fac. Med. Vet., 21, $61-71$.

[15]. Sami, F. (2014), Effect of age and sex on haematological and biochemical parameters of African black neck ostrich in Egypt, $7^{\text {th }}$ Intern. Poultry Conf. - Proceeding, 3 - 6 Nov., 2014, Ain Sukhna, Red sea, Egypt, pp. 334 - 343.

[16]. Serway, A. \& Jewett, W. (2002),Principle of Physics, A Calculus Based Text, $3^{\text {rd }}$ edition, Thompson Learning, Inc. U.S.A. pp. 916 918.

[17]. Taylor, D., Green, N. \& Stout, G. (1997),Biological Sciences. $3^{\text {rd }}$ edition, Cambridge University Press, U.S.A., pp. 461-463.

[18]. Theml, H., Diem, H. \&Haferlach, T.(2004),Color Atlas of Haematology, $2^{\text {nd }}$ revised ed., Georg ThiemeVerlag, New York, NY10001, USA, pp. 29 - 40, 52 - 58, 63 - 80. ISBN 1-58890-193-9.

[19]. Thide, B. (2004),Electromagnetic Field Theory, downloaded from http://www.plasma.uu.se/CED, ISBN 978-0-486-4773-2

[20]. Wolfgang, B. \& Garry, D. (2011),University Physics with Modern Physics. McGraw - Hill Companies, Inc. U.S.A.,pp. 1000 -1002. 